\title{
Ferumoxsil Oral Suspension
}

National Cancer Institute

\section{Source}

National Cancer Institute. Ferumoxsil Oral Suspension. NCI Thesaurus. Code C62485.

An orally administered aqueous suspension of silicone-coated, superparamagnetic iron oxide used as a magnetic resonance imaging (MRI) contrast agent. After oral administration, ferumoxsil fills the stomach and intestines. Upon exposure to the strong external magnetic field during MRI, ferumoxsil exhibits strong T1 relaxation properties and a strongly varying local magnetic field; $\mathrm{T} 2$ relaxation is enhanced, thereby darkening the contrast agent-containing portion of the gastrointestinal tract. Delineation of the bowel is thus enhanced, distinguishing bowel from organs and tissues adjacent to the upper regions of the gastrointestinal tract. 